\title{
New insights on the pre-eruptive volatile budget of Vulcano Island (Italy) magmas: clues from apatite composition
}

\author{
PAOLO FULIGNATI ${ }^{1}$, SIMONE COSTA ${ }^{2,3}$, ANNA \\ GIONCADA $^{3}$, MARCO PISTOLESI ${ }^{3}$ AND EVELINA \\ DALLARA $^{3}$ \\ ${ }^{1}$ Dipartimento di Scienze della Terra, University of Pisa \\ ${ }^{2}$ Università di Pisa \\ ${ }^{3}$ University of Pisa \\ Presenting Author: paolo.fulignati@unipi.it
}

New insights on the pre-eruptive volatile budget of Vulcano Island (Italy) magmas: clues from apatite composition

Fulignati P. ${ }^{1}$, Costa S. ${ }^{1,2}$, Gioncada A. ${ }^{1}$, Pistolesi M. ${ }^{1}$, Dallara E. ${ }^{1}$

${ }^{1}$ Dipartimento di Scienze della Terra, Università di Pisa, via S. Maria, 5356126 Pisa, Italy

${ }^{2}$ Dipartimento di Scienze della Terra, Università di Firenze, via La Pira, 450121 Firenze, Italy

Apatite is a common accessory mineral in magmatic rocks and ore-forming environments, and has received increasing attention as a powerful tool for geochemical and petrological research, because its structure can incorporate many elements such as volatiles $(\mathrm{F}, \mathrm{Cl}, \mathrm{OH}, \mathrm{S}, \mathrm{C})$, trace elements $(\mathrm{Sr}, \mathrm{U}, \mathrm{Th})$, and the rare earth elements (REE). Furthermore, apatite is, in most cases, weakly affected by the alteration and metamorphic processes and, therefore, the geochemical compositions of magmatic apatite is generally well preserved. For these reasons, analyses of apatite chemistry can provide crucial constraints on the raw concentrations, fugacities, and the overall behaviors of volatiles in magmas and coexisting fluids. Thus, apatite has been applied as geochemical tool to monitor magmatic volatile behavior during melt and fluid evolution and to provide constraints on how volatiles partition between apatite, fluids, and melts as magmas ascend through the crust, cool and crystallize.

Vulcano is a well-studied volcanic island in the Aeolian Arc (Italy), with an active center lastly erupted in 1888-90. Information on the volatile content of the Vulcano shoshonitic magmas and on volatile loss during magmatic evolution came mostly from melt inclusions, although these can only be studied in phenocrysts of explosively quenched products. Here we present the analyses of volatile elements in volcanic apatite combined with apatite-melt thermodynamic model [1]. The main aim is to increase the knowledge of the pre-eruptive magmatic volatile budget of magmas erupted at Vulcano in the last $50 \mathrm{kys}$, determining volatile fugacities and the water content of the magmatic suite.

References

[1] Li \& Costa (2020), Geochim. Cosmochim. Acta 269, 203222. 